\title{
Predilection Role Diabetes Mellitus and Dyslipidemia in the Onset of Ischemic Stroke
}

\author{
Jasminka Djelilovic-Vranic ${ }^{1}$, Azra Alajbegovic ${ }^{1}$, Velija Zelija-Asimi ${ }^{2}$, Maida Niksic ${ }^{3}$, Merita Tiric-Campara ${ }^{1}$, Senka Salcic ${ }^{4}$, Azra Celo ${ }^{5}$ \\ Neurology Clinic, Clinical Center of Sarajevo University, Bosnia and Herzegovina ${ }^{1}$ \\ Clinic of Endocrinology, Clinical Center of Sarajevo University, Bosnia and Herzegovina² \\ Clinic of Radiology, Clinical Center of Sarajevo University, Bosnia and Herzegovina ${ }^{3}$ \\ General Hospital "Dr Abdulah Nakas", Sarajevo, Bosnia and Herzegovina ${ }^{4}$ \\ Primary Health Care Center llijas, Bosnia and Herzegovina ${ }^{5}$
}

\begin{abstract}
ntroduction: Stroke is the third leading cause of mortality, disability and dementia, but leading cause of epileptic manifestations in the elderly. Diabetes mellitus as permanently elevated blood glucose, often accompanied by dyslipidemia, is among the leading causes of atherosclerotic alteration in blood vessels and is also increasing in the world. Goal: To determine the existence and predilection of diabetes mellitus and dyslipidemia, in the development of ischemic stroke. Material and methods: During the 2011 are analyzed all people with stroke admitted at the Neurology Clinic. All patients underwent neurological tests and the laboratory test with special emphasis on the value of blood glucose and lipid levels, with brain CT which confirmed the existence of a stroke, EEG and internist examination. Results: During the one-year period the stroke was confirmed in 1184 patients, aged 33-81 years and $37 \%$ in the younger age group (up to 50 yrs.). There was 50.67\% male and 49.33\% female patients. Ischemic stroke was confirmed in 78.0\% (56\% with thrombotic and $22 \%$ with embolic genesis), of which the $32 \%$ was lacunar infarcts (up to 1.5 $\mathrm{cm}$ ) and hemorrhagic in 22\% (SAH in 4.8\%, and intracerebral hemorrhage in 17.2\%). The most frequent risk factors were hypertension $85 \%$, then smoking in 65\%, diabetes mellitus in $39.0 \%$, in $27.38 \%$ dyslipidemia, previous stroke in $26.69 \%$, in $23.57 \%$ arrhythmia In the baseline sample $30.06 \%$ of patients had previously diabetes mellitus and in $8.94 \%$ the diabetes was diagnosed during hospitalization, while dyslipidemia was known from earlier in $22.0 \%$ and in $5.38 \%$ cases was detected during the hospitalization. Among treated patients $79.01 \%$ survived, while $20.09 \%$ have a fatal outcome. Conclusions: Diabetes mellitus and dyslipidemia, along with hypertension and smoking are the leading risk factors for the occurrence of stroke. By timely detection and treatment can be controlled slow atherosclerotic changes in blood vessels and thus prevent stroke. Key words: stroke, diabetes mellitus, dyslipidemia.
\end{abstract}

Corresponding author: prof. Jasminka Djelilovic-Vranic, MD, PhD. Neurology Clinic, Clinical Center of Sarajevo University. Bolnicka 25, 71000 Sarajevo, Bosnia and Herzegovina. E-mail: jasminka000@ bih.net.ba

\section{INTRODUCTION}

Stroke - cerebrovascular insult is among the leading causes of death worldwide after cardiovascular diseases and cancer (10-15\% overall mortality) and in some countries even the leading cause (1). In addition it is the leading cause of disability and demen- treatment could influence reduction of complications.

By definition, diabetes mellitus is a metabolic disorder characterized by abnormal glucose metabolism in terms of chronic hyperglycemia, but at the same time disturbed metabolism of lipids and proteins. This disorder accelerates atherosclerosis and induces microangiopathy (changes in retinal blood vessels, nerves, and kidneys) and macroangiopathy (changes in blood vessels of the heart, brain and limbs) (1). There are two types of diabetes mellitus, Type I occur in children and at younger age and it is an autoimmune disease in which there is destruction of the beta cells of Langerhans islands, causing lack of insulin and the insulindependent diabetes. Type II occurs in the elderly population and is also called insulin-independent diabetes, because in this case the cells develop resistance to insulin. Therefore, although there is production of insulin occurs chronic hyperglycemia (2).

It accompanies $10-35 \%$ of patients with stroke. Conditional variable factor are cardiac disease as a frequent source of emboli and various heart rhythm disorders. Hyperlipidemia is often companion of elevated blood sugar levels and also one of the factors that increase the degenerative changes in blood vessels. The third group of factors is bad 
habits: smoking, alcohol consumption, low physical activity and obesity. Stress that is very topical lately, through the hypothalamic-pituitary axis and a genetic predisposition (3). Ischemic stroke can be caused by a narrowing of blood vessel lumen by thrombotic masses, or clogging of the same lumens embolus from the heart or remote parts or the body. Special form of ischemic stroke is lacunar infarcts-up to $15 \mathrm{~mm}$ where neurological deficit occurs rapidly, but with a tendency of rapid regression and can mimic TIA. Lacunar infarcts are repetitive and resolves without acute neurological disorders, but repeated lacunar infarctions often leads to a variety of psychiatric disorders and dementia (4).

\section{GOAL}

To establish the existence of diabetes mellitus and dyslipidemia in patients with stroke.

\section{MATERIAL AND METHODS}

This paper analyzes all patients with stroke in 2011 and to all the patients are done the neurological exam accompanied by laboratory tests with special emphasis on the value of serum glucose and lipid profile, with monitoring of blood pressure and other risk factors, as well as CT scan (to confirm stroke), ECG and examination by internal diseases specialist.

\section{RESULTS}

During the one-year period, the stroke was confirmed in 1184 patients aged $33-81$ years from which $50.67 \%$ are male and $49.33 \%$ female.

\begin{tabular}{|l|l|l|l|}
\hline Gender & Male & Female & Total \\
\hline No. (N) & 600 & 584 & 1184 \\
\hline Percent (\%) & 50.67 & 49.33 & 100.00 \\
\hline
\end{tabular}

Table 1. Gender structure

Ischemic stroke was confirmed in $78.10 \%$, from which $56 \%$ of thrombotic and $22.1 \%$ of embolic type, out of which $32 \%$ were lacunar and hemorrhagic and was present in $22.0 \%$, SAH in $4.8 \%$ and intracerebral hematoma in $17.2 \%$.

Analyzing the risk factors in our sample, the most common were hypertension in $85 \%$, then $65 \%$ smoking, dia-

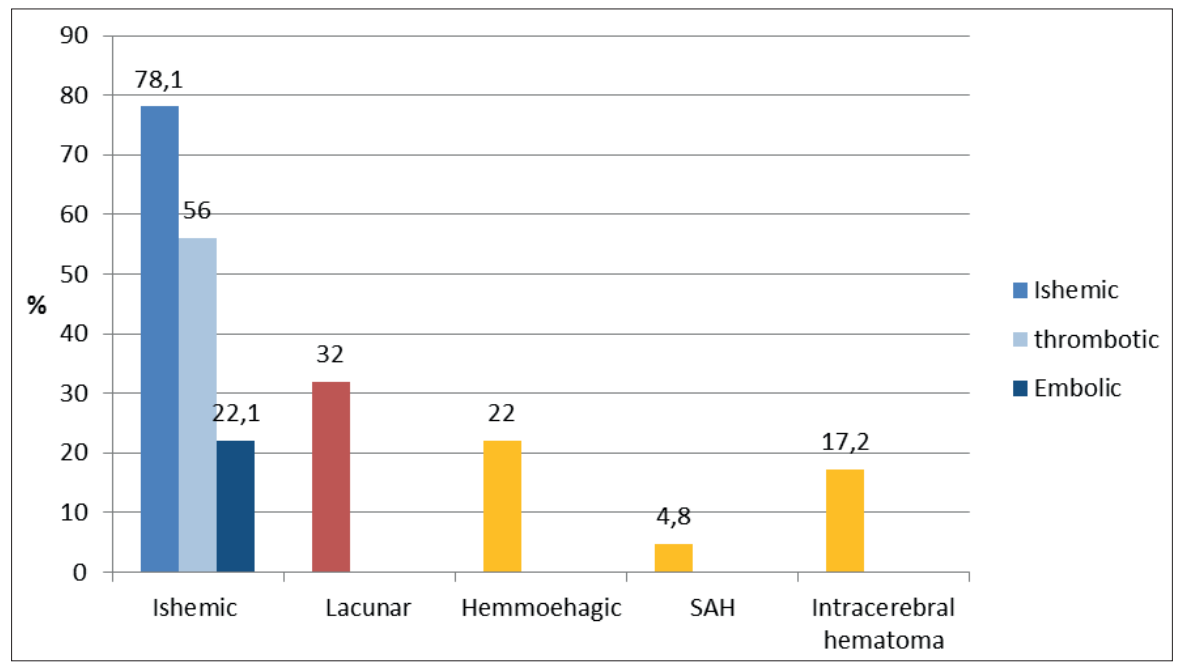

Figure 1. Stroke type

betes mellitus in $39.0 \%, 27.38 \%$ dyslipidemia, previous stroke at $26.69 \%$ and $23.57 \%$ arrhythmia.

In the group of patients with diabe-

Terént, which was a systematic review of 98 articles around the world on the topic of gender differences among patients with stroke, it was concluded that tes, previous diabetes had and was treated $30.06 \%$ of patients while in $8.94 \%$ the disease was diagnosed after the stroke. Insulin therapy was applied in $42.06 \%$ of the total number of patients with diabetes, the per oral therapy in $50 \%$ of patients and $7.94 \%$ of the total number of patients with diabetes was not treated at all.

Dyslipidemia was present in $27.38 \%$ of patients, the same was known earlier in $22.0 \%$ and at $5.38 \%$ was newly discovered. Diabetes with dyslipidemia was present in $21 \%$ of patients, hypertension with diabetes had $38 \%$ of pa-

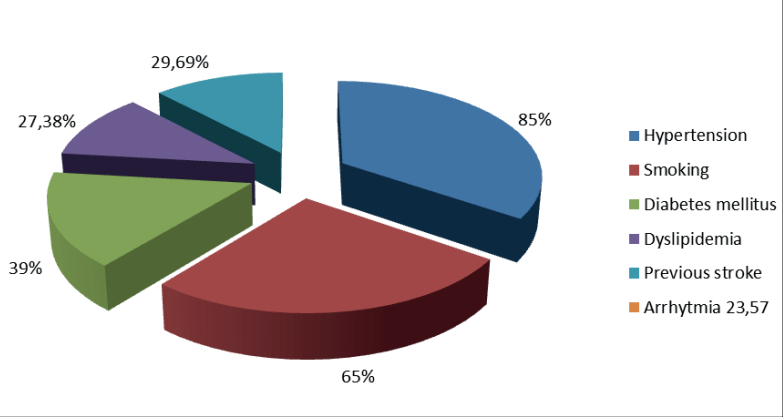

Figure 2. Risk factors

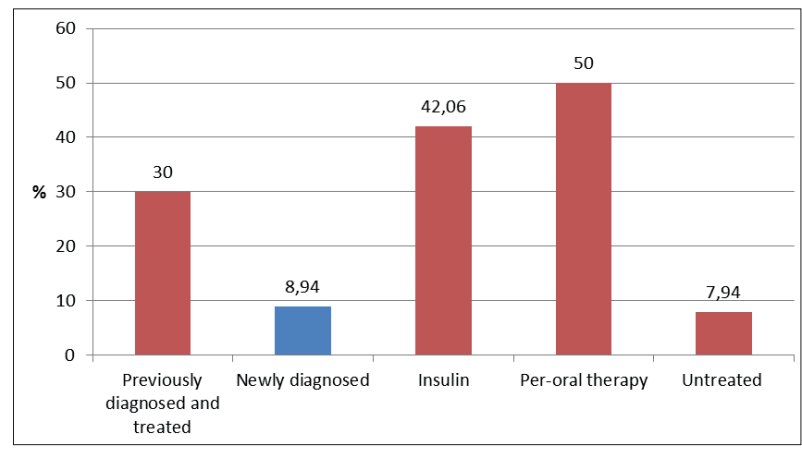

Figure 3.Diabetes treatment tients, diabetes, hypertension and dyslipidemia was present in $27.5 \%$ of patients.

From the total number of stroke patients, survived (during treatment) $79.01 \%$ and $20.09 \%$ had lethal outcome.

\section{DISCUSSION}

In our study from the total number of stroke patients there was $50.67 \%$ male and $49.33 \%$ female patients.

In a study carried out by Peter Appelros, Birgitta Stegmayr and Andreas the stroke is more frequent in male patients compared to female patients (5).

The age ranged from 33-81 years, with fact that $17 \%$ of patients were younger (up to 50 years).

U.S. National Institute of Neurological Disorders and Stroke states that the age is the leading risk factor of stroke and that $95 \%$ of all episodes occur in people older than 45 years, while two thirds of all episodes occur in people older than 65 years (6). In our study, 87\% 


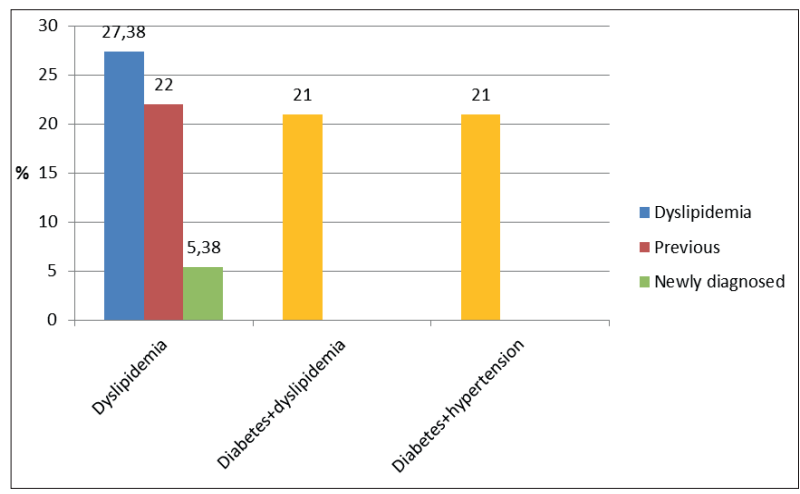

Figure 4. Dyslipidemia and hypertension in group of patients with diabetes

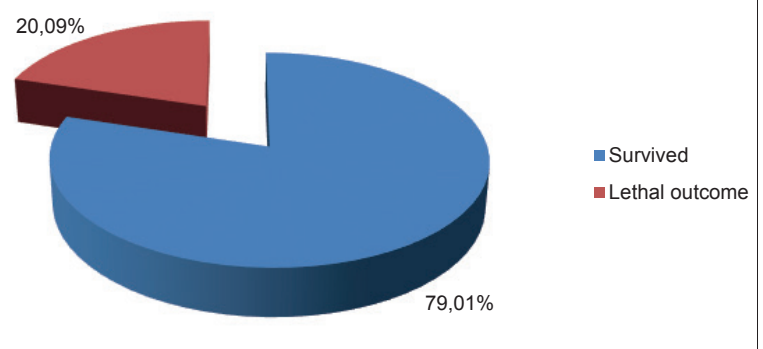

Figure 5. Treatment outcome

of strokes were in the age group over 50 years of age which is in accordance with world results.

Under the age of 40 years, men are present at $0.40 \%$ and women with $0.00 \%$, at age group $50-59$ years, males account for $10.32 \%$ and women for $3.97 \%$, while in age group 60-69 years men account for $12.70 \%$ and women for $11.11 \%$ compared to the total number of all patients with a diagnosis of stroke, while in the age group over 70 years there is a greater proportion of women (14.52\% F to $11.5 \% \mathrm{M})$

Specifically, this study showed that the higher incidence of illness is among elderly women compared to men, which is in accordance with research by Demarin V, Trkanjca Z and Seric V and the Croatian society for the prevention of stroke who claim that men are more prone to stroke in reproductive and women at the age after the menopause (7).

In addition to age, there are a large number of risk factors that affect the development stroke and we follow in this paper: hypertension, diabetes mellitus, dyslipidemia, previous stroke and arrhythmias.

Hypertension as a risk factor was found in $85.0 \%$, smoking in $65 \%$, dia- betes mellitus in $39.0 \%$, dyslipidemia in $27.38 \%$ patients and $26.69 \%$ had previous history of stroke. Genetic factor was present in $7.54 \%$. This study showed that diabetes mellitus and dyslipidemia, as risk factors, taking third and fourth place in frequency relative to other risk factors.

U.S. National Institute of Neurological Disorders and Stroke states that the existence of diabetes mellitus as a risk factor for stroke is same as have 15 years more than the actual age. Patients with diabetes mellitus have a 3 times greater risk of developing stroke compared to patients who without diabetes, and also often have some other risk factors, thus the overall risk of stroke morbidity multiplies (8).

Patients with diabetes in this study used a different type of therapy. In percent, $42.06 \%$ of patients used insulin in the treatment, $50.00 \%$ used oral anti-diabetes therapy, while $7.94 \%$ of patients was without any therapy for diabetes.

These results show that a better control of diabetes was established in those patients who use insulin in the treatment, compared to those who used oral anti-diabetics and that the higher risk for the occurrence of stroke is in those patients who used oral anti-diabetics in therapy due to poor disease control.

Demarin V, Bosnjak-Pasic $M$ and Bosnar-Puretić $M$ in their study presented the fact that diabetes mellitus is a major risk factor for cerebrovascular disease and progression of atherosclerosis. Of the five people who have experienced a stroke, one in its history has records of previous diabetes. This study showed twice the incidence of diabetes mellitus as a risk factor for the occurrence of stroke in relation to the data produced by the aforementioned authors. The explanation for this difference in results can be found in older pa- tients in this study, because even at $83 \%$ of patients was older than 50 years (9).

Dyslipidemia is one of the major risk factors for the cerebrovascular disease. In numerous studies it has been observed that elevated levels of cholesterol and triglyceride in the serum leads to the accelerated development of atherosclerosis. Accelerates development of atherosclerosis is especially present with high levels of LDL-cholesterol or so called „bad“ cholesterol (low-density lipoproteins, which represent a fraction of cholesterol) versus "good“ HDL cholesterol (high-density lipoprotein, which reduces the risk of developing atherosclerosis).

On dyslipidemia, or the development of atherosclerosis, it can be influenced primarily by healthy diet, physical activity and use of statins. In our study, $27.38 \%$ patients had dyslipidemia, particularly cholesterol. A recent metaanalysis, which included data from studies CARE and $4 S$ confirmed that the overall risk reduction is $31 \%$ by the use of statins (pravastatin and simvastatin) for the development of all forms of stroke, except for those with a fatal outcome (10).

In percent, $10.91 \%$ of the total number of patients involved in the study, has diabetes mellitus and dyslipidemia as risk factors, or approximately one out of nine patients in the study have both risk factors.

Research conducted in several cities in Bosnia and Herzegovina (Mostar, Livno, Tuzla) showed that dyslipidemia as a risk factor is present in $11.3 \%$ of patients with diabetes mellitus who developed stroke (11).

The study by Djelilovic-Vranic J, Alajbegovic A, Tiric-Campara M, and Todorovic Lj. in 2009 in Sarajevo shows that dyslipidemia as a risk factor was found in $48.65 \%$ of patients aged between 18 and 49 years, while in $24.43 \%$ of patients of the same age was found diabetes mellitus as a risk factor. Data collected by these authors differs from the results reached in this study $(42.46 \%$ of patients with diabetes and $27.38 \%$ of patients with dyslipidemia). The reason for the discrepancy mentioned is due to the different populations involved in these studies, as this study included all ages, while in the previously mentioned 
study included only younger age groups (18-49 years) (12).

When the outcome of the disease is in question, in this study it was found that $79.01 \%$ of the patients survived and 20.09\% have lethal outcome. The results of this study are consistent with the results obtained by Ingall $\mathrm{T}$ at the Mayo Clinic in Arizona. Mentioned authors found that the survival of people diagnosed with stroke in the United States in the 2004 was $76.43 \%$ (13).

\section{CONCLUSIONS}

Ischemic stroke is more common than hemorrhagic.

The most common risk factors for stroke are hypertension, smoking, diabetes mellitus, dyslipidemia, previous stroke and heart rhythm disturbances.

Early detection of risk factors, especially diabetes and dyslipidemia and their adequate treatment contributes certainly to complications reduction at blood vessels and thus also reduces the likelihood of stroke.

\section{REFERENCES}

1. Gamulin S, Marušić M, Kovač Z. i saradnici, Patofiziologija, šesto, obnovljeno i izmijenjeno izdanje, Knjiga prva, Medicinska naklada; Zagreb, 2005: 170-212.

2. Bongers $\mathrm{T}$, de Maat M, van Goor $\mathrm{M}$ et al.; High von Willebrand factor levels increase the risk of first ischemic stroke: influence of ADAMTS13, inflammation, and genetic variability. Stroke. 2006; 37 (11): 2672-2677.

3. Jenkins G, Who is at risk of stroke. BBC Health News, 2010.

4. Petrea RE, Beiser AS, Seshadri S, KellyHayes M, Kase CS, Wolf PA; Gender Differences in Stroke Incidence and Poststroke Disability in the Framingham Heart Study; American Stroke Association; SAD, 2008.

5. Appelros P, Stegmayr B, Terent A. Sex Differences in Stroke Epidemiology-A Systematic Review; American Stroke Association, Stroke. 2009; 40: 1082-1090.

6. Donnan GA, Fisher M,Macleod M, Davis SM (May 2008)."Stroke". Lancet. 371
9624: 1612-1623.

7. Demarin V, Trkanjec Z, Šerić V. Moždani udar; Hrvatsko društvo za prevenciju moždanog udara. Hrvatska, 2010.

8. National Institute of Neurological Disorders and Stroke; Brain Basics: Preventing Stroke; SAD, 2012.

9. Demarin V, Bošnjak-Pašić $M$, BosnarPuretić M. Moždani udar-vodeći uzrok invaliditeta; Hrvatsko društvo za prevenciju moždanog udara; Hrvatska, 2011.

10. Blaw G, Lagaay A, Smelt A, Westendorp R. Stroke, statins and cholesterol. A meta-analysis of randomised, placebo-controlled, double-blind trials with HMG-CoA reductase inhibitors, Stroke. 1997; 28: 946-950.

11. Škobić H, Badrov A, Pejanović-Škobić N, Sinanović O. Diabetes mellitus is more frequent in ischemic than in hemorrhagic stroke. Neurologia Croatica. 2007; 56, Suppl 5: 124-125.

12. Đelilović-Vranić J, Alajbegović A, TirićČampara M, Todorović $\mathrm{Lj}$. Stroke at a younger age. Acta Clin Croat. 2011; 50: 185-191.

13. Ingall T. Stroke - incidence, mortality, morbidity and risk. J Insur Med. 2004; 36(2): 143-152.

\section{instructions for the authors}

All papers need to be sent to: Editorial board of the journal "Medical Archives (Med Arh)", electronically over the web site www.scopemed.org. Every sent article gets its number, and author(s) will be notified if their paper is accepted and what is the number of paper. Every correspondence will use that number. The paper has to be typed on a standard format (A4), leaving left margins to be at least $3 \mathrm{~cm}$. All materials, including tables and references, have to be typed double-spaced, so that one page has no more than 2000 alphanumerical characters (30 lines) and total number of used words must not to be more than 3,500 . Presenting paper depends on its content, but usually it consists of a title page, summary, tex $t$ references, legends for pictures and pictures. type your paper in MS Word and send it on a diskette or a CD-ROM, so that the editing of your paper will be easier.

Title page. Every article has to have a title page with a title of no more than 10 words: name(s), last and first of the author(s), name of the institution the author(s) belongs to, abstract with maximum of 45 letters (including space), footnote(s) with acknowledgments, name of the first author or another person with whom correspondence will be maintained.

Summary. The paper needs to contain structured summary, 200 words at the most. Summary needs to hold title, full name(s) and surname(s) of the author(s) and coauthor(s), work institution, and all essential facts of the work, introduction, formulation of problems, purpose of work, used methods, (with specific data, if possible) and basic facts. Summary must contain the re- view of underlined data, ideas and conclusions from text. Summary must have no quoted references. Four key words, at the most, need to be placed below the text.

Central part of the article. Authentic papers contain these parts: introduction, goal, methods, results, discussion and conclusion. Introduction is brief and clear review of the problem. Methods are shown, so that interested reader is able to repeat described research. Known methods don't need to be identified, they are cited (referenced). If drugs are listed, their generic name is used, (brand name can be written in brackets). Results need to be shown clearly and logically, and their significance must be proven by statistical analysis. In discussion, results are interpreted and compared to the existing and previously published findings in the same field. Conclusions have to give an answer to author 's goals.

References. Quoting references must be on a scale, in which they are really used. Quoting most recent literature is recommended. Only published articles, (or articles accepted for publishing), can be used as references. Not published observations and personal notifications need to be in text in brackets. Showing references must be as how they appear in the text. References cited in tables or pictures are also numbered according to the quoting order. All references should be compiled at the end of the article in the Vancouver style or pubMed style (i.c. www.scopemed.org).

Statistical analysis. Tests used for statistical analysis need to be shown in text and in tables or pictures containing statistical analysis.

Tables and pictures. Tables have to be numbered and shown by their order, so they can be understood without having to read the paper. Every column needs to have a title, every measuring unit (SI) has to be clearly marked (i.e. preferably in footnotes below the table, in Arabic numbers or symbols). Pictures also have to be numbered as they appear in the text. drawings need to be enclosed on a white or tracing paper, while black and white photos have to be printed on a radiant paper. Legends (e.g. next to pictures and photos), have to be written on a separate A4 format paper. All illustrations, (pictures, drawings, diagrams), have to be original, and on their backs contain, illustration number, first author 's last name, abbreviated title of the paper and picture at the top. It is appreciated, if author marks the place for the table or picture.

Use of abbreviations. Use of abbreviations have to be reduced to a minimum. Conventional units can be used without their definitions. Supplement. If paper contains original contribution to a statistical method or author believes, without quoting original computer program, that paper 's value will be reduced. Editorial staff will consider possibility of publishing mathematics /statistic analysis in extension.

Important policies. Any practice of plagiarism will not be tolerated regarding submitted articles. Non-identifiable quoted parts of the articles from other authors are known act of plagiarism if it is not cited or referencing in appropriate places in the article. Advertent practice of plagiarism will abort reviewing process or article submission. Author(s) may suggest or exclude peer-re-viewers for their articles but Editorial Board has the right to reject their(s) opinions or suggestions according to copyright Assignment form signed by authors before reviewing process. Authors must respect guidelines and rules of IcMjE, WAME, COpE, E A SE, linked on www. avicenapublisher.org.

Authorship. All individuals listed as authors should qualify for authorship and should have participated sufficiently in the work to take public responsibility for appropriate portions of the content and follow the next conditions: a) substantial contributions to the conceptions and design, acquisition of data, or anal- lysis and interpretation of data; of data, or anal- lysis and interpretation of data;
b) drafting the article or revising it critically for b) drafting the article or revising it critically for
important intellectual content; c) final approval of the version to be published (all co-authors must sign copyright Assignment form downloaded from www.avicenapublisher.org). All other contributors to the article's subject who does not qualify for authorship should be listed in acknowledgement section. for all relevant information about authorship follow IcMjE guidelines.

Conflict of interest. All authors must make a formal statement at the time of submission indicating any potential conflict of interest that might constitute an embarrassment to any of the authors if it were not to be declared and were to emerge after publication. Such conflict of interest might include, but not limited to, share holding in or receipt of grant or consultancy free form a company whose prodor consultancy free form a company whose prodmanufactures a competing product. All authors must submit a statement of conflict of Interest to be published at the end of their article (conflict of Interest: NONE DECLARED). 